DOI: $10.4274 /$ tftr.33600

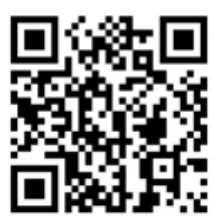

\title{
Gövde Ortezi Kullanan İdiyopatik Skolyozlu Adolesanlarda Bad Sobernheim Stres Sorgulama Formunun Türkçe Adaptasyonu ve Güvenirliği
}

\author{
Turkish Adaptation and Reliability of Bad Sobernheim Stress Questionnaire in \\ Adolescents With Idiopathic Scoliosis Using Spinal Brace
}

\author{
Hürriyet Gürsel YILMAZ*, Tuğba KURU, Güneş YAVUZER* \\ Istanbul Üniversitesi, Sağlık Bilimleri Fakültesi, Fizyoterapi ve Rehabilitasyon Bölümü, Istanbul, Türkiye \\ *Haliç Üniversitesi Sağık Bilimleri Yüksek Okulu Fizyoterapi ve Rehabilitasyon Bölümü, Istanbul, Türkiye
}

Özet

Amaç: Tıbbi alanda çalışan profesyonellerin stres ve yaşam kalitesi alanındaki ilgileri artmaktadır. Adolesan Idiyopatik Skolyoz (AIS) nedeniyle gövde ortezi kullanan hastaların stres düzeyini değerlendirebilecek Türkçe bir sorgulama formu mevcut değildir. Bu çalışmada alandaki eksiklikler göz önüne alınarak Bad Sobernheim Stres Sorgulama (BSSS) Formu Türkçe'ye çevrildi ve gövde ortezi kullanan AIS hastalarında ölçüm güvenilirliği araştıııldı.

Gereç ve Yöntem: Çalışmaya 8-17 yaşları arasında AIS tanısı almış ve en az iki aydır günde 20-23 saat aynı tip "CAD-technique" (Regnier sistemChêneau brace) gövde ortezi kullanan 38 adolesan (31 kız, 7 erkek) dahil edildi. Tüm katılımcılara bir hafta arayla toplam iki kez uygulanan Türkçe BSSS Formu'nun test-tekrar test (Pearson Korelasyon Analizi) ve içsel tutarlılık (Cronbach alfa) analizleri yapıldı.

Bulgular: Çalışmaya katılan adolesanların yaş ortalaması $13,47 \pm 2,93$ yıl, Cobb açısı 39,05 $\pm 11,17$ dereceydi. Türkçe BSSS Formu'nun içsel tutarlılığı analizinde Cronbach alfa katsayısı 0,88 olarak belirlendi. Test-tekrar test değerlendirmesinde, bir hafta arayla iki kez uygulanan sekiz sorunun korelasyon katsayıları 0,647 $(p=0,003)$ ile 0,978 $(p=0,001)$ arasında değişim gösterdi.

Sonuç: Bu çalışmada AIS nedeniyle gövde ortezi kullanan hastalarda Türkçe BSSS Formu'nun içsel tutarlılığı yüksek bulunmuş ve test-tekrar testlerle yüksek düzeyde güvenilir olduğu gösterilmiştir. Çalışma sonucunda elde edilen Türkçe BSSS Formu'nun gövde ortezi kullanan AIS'lı Türk hastaların stres değerlendirmesinde kullanılabilecek pratik ve güvenilir bir araç olduğu gösterilmiștir. Türk Fiz Tıp Rehab Derg 2012;58:225-8.

Anahtar Kelimeler: Skolyoz; stres; psikolojik; ortez; güvenilirlik

\section{Summary}

Objective: Interest of health professionals has been increased on stress and quality of life. Currently, there is no questionnaire in Turkish language to evaluate the stress level of adolescents with idiopathic scoliosis. Considering this deficiency in the field, the Bad Sobernheim Stress Questionnaire (BSSQ) was translated into Turkish and reliability of the questionnaire was evaluated on adolescents with idiopathic scoliosis using spinal orthoses.

Metarials and Methods: Thirty-eight adolescents (31 girls, 7 boys, aged 8-17 years) with idiopathic scoliosis and using same type of spinal orthoses, "CADtechnique" (Regnier system-Chêneau brace) for 20-23 hours per day for at least two months were included in the study. Test-retest reliability (Pearson Correlation Coefficient) and internal consistency of the scores were evaluated using the Turkish BSSQ scores collected from the participants twice, one week apart.

Results: The mean age of the adolescents was $13.47 \pm 2.93$ years and the mean Cobb angle was $39.05 \pm 11.17$ degrees. In terms of internal consistency of Turkish BSSQ, Cronbach alfa was calculated as 0.88 . Test-retest analysis of the scores, collected twice one week apart, revealed correlation coefficients changing from $0.647(p=0.003)$ to $0.978(p=0.001)$.

Conclusion: In this study, we reported high test-retest reliability and internal consistency of the Turkish BSSQ on adolescents with idiopathic scoliosis using spinal ortheses. The Turkish BSSQ created in this study is a practical and reliable scale to evaluate stress levels in Turkish adolescents with idiopathic scoliosis. Turk J Phys Med Rehab 2012;58:225-8.

Key Words: Scoliosis; stress; psychological; braces; reliability

Yazışma Adresi/Address for Correspondence: Dr. Hürriyet Gürsel Yılmaz, Haliç Üniversitesi Sağlık Bilimleri Yüksek Okulu Fizyoterapi ve Rehabilitasyon Bölümü, İstanbul, Türkiye Tel.: +902862635950 E-posta: yilmazhurriyet@gmail.com 


\section{Giriş}

Skolyoz, omurganın lateral deviasyonu ile birlikte rotasyonun da bulunduğu üç boyutlu deformitesidir (1). Adolesan İdiyopatik Skolyoz (AIS) en sık rastlanan skolyoz tipidir ve 10-16 yaşları arasındaki çocuklarda \%2-4 oranında görüldüğü bildirilmektedir $(2,3)$. Ülkemizde skolyoz prevelansını belirlemek amacıyla planlanan geniş kapsamlı bir çalışma bulunmamakla birlikte, üç farklı ilimizde yapılan okul taramalarında skolyoz sıklığı \%0,2-4 arasında bildirilmiştir (4,5). Giresun III Sağlık Müdürlüğü’nce 12 okulda 12-14 yaşlarında 1455 öğrenci taranmış ve 105 skolyoz olgusu $(\% 7,2)$ saptanmıştır (6). Skolyoz Destek Grubu ise Türkiye'de 2,5 milyon skolyoz hastası olduğunu belirtmektedir (7).

AIS karmaşık ve ilerleyici bir durumdur. Gerek etkilediği bireylerin yaşı, gerekse vücut imajı üzerinde oluşturduğu olumsuz etki nedeniyle kişinin yaşam kalitesini önemli ölçüde etkiler (8). AIS tedavisinde birincil hedef deformitenin ilerlemesini önlemek olmalıdır $(1,9)$. Literatüre göre AIS'ın konservatif tedavisinde en yaygın kullanılan yöntemler skolyoza özel egzersizler, farklı gövde ortezleri ve elektrik stimülasyonudur. $(1,10-13)$ Konservatif tedavide Cobb açısının derecesine, hastanın maturasyon durumuna ve teşhis yaşına göre ortez kullanım endikasyonu ortaya çıkabilir $(1,9,14)$. Ortez kullanımı başladığında hastanın yaşamı olumsuz yönde etkilenir ve yüksek seviyede stres ortaya çıkabilir $(8,12)$. Kinal ve ark. $(15)$ 'nın yaptığı çalışma gövde ortezi kullanımının adolesanların yaşam kalitesini kendi spinal deformitelerinden daha çok etkilediğini ortaya koymuştur (15). Yapılan araştırmalar adolesan çocuklardaki psikolojik stresin yaşam kalitesi üzerine direkt etkisi olduğunu göstermişlerdir (9). Skolyozu nedeniyle adolesan dönemde gövde ortezi kullanan hastaların psikolojik streslerini değerlendirmek amacıyla Katharina Schroth Spinal Deformiteler Rehabilitasyon Merkezi'ndeki araştırmacılar tarafından "BSSSBad Sobernheim Stres Sorgulama Formu" geliştirilmiş ve geçerlilik çalışmaları yapışmıştır (15). BSSS Formu, psikolojik strese odaklanan 8 kısa sorudan oluşmaktadır (Ek-1). Her bir sorunun cevabı 0 (en yüksek stres) - 3 (en düşük stres) arasında puanlanmaktadır. En yüksek puan toplamı olan 24 en düşük stres olarak hesaplanır (14-16). Sıfır-8 puan arası yüksek stres, 9-16 puan arası orta düzeyde stres ve 17-24 puan arası düşük stres olarak kabul edilmektedir (15).

Orjinali Almanca olan BSSS Formu'nun İngilizce, İspanyolca ve Polonya dilinde adaptasyonları yapılmış ve adölasanlarda orteze bağlı stres düzeyi sorgulanmıştır (15-18). Kullanılan gövde ortezinin özelliğine bağlı stres değişiklikleri de araştırılmıştır (14). AIS tanısı ile gövde ortezi kullanan hastaların, orteze bağlı streslerini ve yaşam kalitelerini değerlendirebilecek özgün Türkçe bir ölçek bulunmamaktadır. Bu nedenle çalışmamızda Türk hastalarda kullanılabilmesi için BSSS Formu'nun Türkçe'ye çevrilmesi ve AIS'lı hastalarda ölçüm güvenilirliğinin değerlendirilmesi amaçlandı.

Tablo 1. Türkçe BSSS Formu'nun birinci ve ikinci uygulamaları arasında korelasyon katsayiları.

\begin{tabular}{|lcc|}
\hline & $\mathbf{r}$ & $\mathbf{p}$ \\
\hline 1. Soru & 0,70 & 0,001 \\
2. Soru & 0,97 & 0,001 \\
3. Soru & 0,91 & 0,001 \\
4. Soru & 0,92 & 0,001 \\
5. Soru & 0,71 & 0,001 \\
6. Soru & 0,64 & 0,003 \\
7. Soru & 0,80 & 0,001 \\
8.Soru & 0,96 & 0,001 \\
Toplam & 0,96 & 0,001 \\
\hline
\end{tabular}

\section{Ek 1. Türkçe Bad Sobernheim Stres Sorgulama Formu.}

1. Korse içinde gövdemin görünümü nedeniyle kendimi rahatsız hissediyorum

$\square$ Kesinlikle doğru $\square$ Doğru sayılı

$\square$ Pek doğru değil

$\square$ Hiç doğru değil

2.Korse ile sosyal olmak benim için çok zor

$$
\square \text { Kesinlikle doğru }
$$

$\square$ Doğru sayılır

$\square$ Pek doğru değil

$\square$ Hiç doğru değil

3.Başkalarının beni korse ile görmesinden rahatsız oluyorum

$$
\square \text { Kesinlikle doğru }
$$

$\square$ Doğru sayılır

$\square$ Pek doğru değil

$\square$ Hiç doğru değil

4.Başkalarının beni korse ile görmesinden utanmıyorum

$$
\square \text { Kesinlikle doğru }
$$

$\square$ Doğru sayılır

$\square$ Pek doğru değil

$\square$ Hiç doğru değil

5.Korse giydiğimi başkalarının anlamaması için onlara dokunmaktan kaçınıyorum

$$
\square \text { Kesinlikle doğru } \square \text { Doğru sayılır }
$$$$
\square \text { Pek doğru değil }
$$

$\square$ Hiç doğru değil

6.Kıyafet seçerken ve saçımı yaparken korsemin görünmediğinden emin olmaya çalışıyorum

$$
\square \text { Kesinlikle doğru } \square \text { Doğru sayilır }
$$

$\square$ Pek doğru değil

$\square$ Hiç doğru değil

7.Yakınlarıma korsemi göstermekten utanmıyorum (ailem, okul arkadaşlarım gibi)

$\square$ Kesinlikle doğru $\square$ Doğru sayılır

$\square$ Pek doğru değil

$\square$ Hiç doğru değil

8.Korse nedeniyle aktivitelerimden, hobilerimden ve diğer yapmayı sevdiğim şeylerden uzak duruyorum

$$
\square \text { Kesinlikle doğru }
$$$$
\square \text { Doğru sayilır }
$$

$\square$ Pek doğru değil

$\square$ Hiç doğru değil 


\section{Gereç ve Yöntem}

Formed Fizik Tedavi ve Rehabilitasyon Kliniğine, Mart 2008 ile Kasım 2010 tarihleri arasında başvuran ve konservatif tedavi olarak gövde ortezi uygulanan 38 idiyopatik skolyozlu adolesan (31 kız, 7 erkek, ortalama yaş: $13,47 \pm 2,93$, en düşük 8 , en yüksek 17) çalışmaya alındı. Dahil edilme kriterleri, idiyopatik skolyoz tanısı ile en az iki aydır günde 20-23 saat arasında gövde ortezi kullanımı, skolyoz dışında mental, ortopedik ya da nörolojik başka bir probleminin olmaması ve çalışmaya katılımı gönüllü kabul etmesiydi. Tüm adolesanların ailelerinden konu ile ilgili izin alındı.

Bu çalışmada kullanılan BSSS Formu'nun Türkçe hali, Beaton tarafından önerilen kültürel adaptasyon algoritmasına göre oluşturuldu (19). Orjinali Almanca olan BSSS formu Türkçe'ye çevrildi. Aynı zamanda İngilizce form da Türkçe'ye ve sonra geri tercüme ile İngilizceye çevrildikten sonra yapılan karşılaştırmalar ile son haline getirildi. Almanca ve İngilizce çeviriler arasında farklılık yoktu. Elde edilen Türkçe Form, deneme amacıyla 15 sağlıkı kişi ile görüşülerek, soruların anlaşılabilirliği açısından test edildi. Anlaşılmasında güçlük olan 2. soru ('korse ile görünmek benim için çok zor') tekrar düzenlendi ve sorgulama formuna son şekli verildi. En az 2 aydır gövde ortezi kullanan hastalar bir hafta arayla toplam iki kez formu doldurdu. Bu bir hafta süresince hastalara ortez dışında bir tedavi uygulanmadı.

Test-tekrar test güvenilirliğinin değerlendirmesi için iki cevap arası korelasyon Pearson İki Uçlu Korelasyon Analizi kullanılarak hesaplandı (20). Korelasyon katsayısının $\geq 0,60$ olması çok iyi korelasyon, 0,31 0,59 orta derecede, $\leq 0,30$ ise zayıf korelasyon olarak değerlendirildi. Soruların içsel tutarlıı̆ı Cronbach alfa katsayısı ile değerlendirildi. Alfa katsayısının 0,80 'den büyük olması halinde içsel tutarlılık çok iyi olarak kabul edildi $(20,21)$.

\section{Sonuçlar}

Çalışmaya alınan 38 olgunun 31'i kız, 7'si erkek olup ortalama Cobb açısı 39,05 $\pm 11,17$ (en düşük 22- en yüksek 56) derece idi. Sorgulama formunu dolduran hastalar ortalama 11,65 111,37 (en düşük 2, en yüksek 30) aydır CAD-technique Regnier systemChêneau tip gövde ortezi kullanmaktaydılar. Kullanılan ortezlerin yirmisi kısa lomber, onsekizi uzun torokolomber gövde orteziydi.

İlk değerlendirmede ortalama toplam stres puanı 11,5 $\pm 5,2$ (en düşük 3- en yüksek 23), ikinci değerlendirmede ise 12,2 \pm 5 ,6 (en düşük 3- en yüksek 23) bulundu. BSSS Formu'nun iki toplam puanı arasındaki korelasyon katsayısı 0,96 olup, her soru için puanlar arası korelasyon katsayıları 0,64 $(p=0,003)$ ile 0,97 $(p=0,001)$ arasında değişim gösterdi (Tablo 1). Sorgulama formunun alt değerlendirmesinde gövde ortezi kullanımı sırasında 38 olgunun 8 'inde (\%21) stres düzeyi yüksek, 22'sinde (\%58) stres düzeyi orta ve $8^{\prime}$ inde (\%21) ise hafif düzeyde idi. Soruların içsel tutarlılı̆ının değerlendirmesinde Cronbach alfa katsayısı 0,88 olarak hesaplandı ve içsel tutarlılık çok iyi olarak değerlendirildi.

\section{Tartışma}

Skolyoz hem omurgada eğrilik hem de gövde ortezi kullanımı nedeniyle adolesanlarda vücut imajını olumsuz yönde etkileyen önemli bir stres nedenidir ve yaşam kalitesini bozar. Konservatif tedavide önemli bir yeri olan ortezlerin, çevresel ve hormonal nedenlerden dolayı stresleri zaten yüksek olan adolesanlarda, stresi daha da arttırdığı gösterilmiştir $(9,22)$.

Günümüzde gövde ortezi kullanan idiyopatik skolyozu olan adolesanlarda yaşam kalitesini ve psikolojik stresi değerlendiren birkaç ölçek bulunmaktadır. Bunlar SRS 22 (Scoliosis Research Society-22 Sorgulama Formu), BSSS ve Br Q (Brace Questionaire)'dur ve farklı dillerde adaptasyonları yapılmıştır. Vasiliadis ve arkadaşları tarafından 2006 yılında geliştirilen Ortez Sorgulama Formu ve orjinali Almanca dilinde hazırlanmış olan BSSS Formu alanda en fazla kullanılanlardır $(16,23)$. Bad Sobernheim'de bulunan Katherina Schroth Spinal Deformiteler Rehabilitasyon Merkezi'nde 2006 yılında Helmus ve ark. (16) tarafından geliştirilmiş olan BSSS formunun AIS'lı hastalarda geçerliliği gösterilmiştir. Helmus ve ark. (16) yaptıkları çalışmada BSSS Formunun güvenilirliğinin $(r=0,88)$ ve içsel tutarlılığı (Cronbach alfa $=0,97$ ) oldukça yüksek olduğunu rapor etmişlerdir. Yine Aulisa ve ark. (24) tarafından yapılan ve SRS 22, BSSS ile Ortez Sorgulama Formunun karşılaştıııldığı bir çalışmada her üç formun da gövde ortezi kullanan AIS'lı bireylerin değerlendirmesinde geçerli ve güvenilir olduğu bildirilmiştir. Aynı çalışmada yaşam kalitesi düzeyinin cins ve ortezin tipine göre değişim gösterdiği de belirtilmiştir.

D'Agata ve ark. (17) tarafından formun İspanyolca'ya adaptasyonu yapılmış ve Cronbach alfa katsayısı 0,80 olarak bulunmuştur. Misterska ve ark. (25) ise BSSS Formunu Polonya diline adapte etmişler ve Cronbach alfa katsayısını 0,97 olarak saptamışlardır. Bizim çalışmamızda da iki değerlendirme arasında korelasyon katsayısı 0,96 ve Cronbach alfa katsayısı 0,88 olarak bulunmuş ve yapılan diğer çalışmalar gibi soruların birbirleriyle uyumu gösterilmiştir. Ayrıca stres alt değerlendirme sonuçlarımız hastaların toplamında \%21, \%58 ve \%21 sıralamasıyla yüksek stres, orta düzeyde stres ve minimal stres olarak bulunmuştur ve bu sonuçlar Helmus ve ark. (16) sonuçları ile uyumludur. Sorgulama formundaki tüm sorularda 0-3 arasında yapılan değerlendirmede en düşük stres puanı 6. soruda 0,68 ve en düşük stres puanı da 7. Soruda 2,15 olarak hesaplandı. Helmus ve ark. (16) çalışmasında da tavan puan 6. soruda elde edilmiştir bu açıdan çalışmamızın sonuçları benzerlik göstermiştir. Her iki çalışmada da adölosan bireyler için en sıkıntılı olan gövde ortezinin günlük kıyafet ve dış görünümlerinde yarattığı farklılıktır. Türk çocukları ile Helmus'un grubundaki farklılık 7. ve 8. soruda ortaya çıkmıştır. Helmus ve arkadaşlarının çalışmasında en alt puan ise 8. soruda ortaya çıkmıştır. Spor aktivitelerinde yaşanan sıkıntı Helmus'un grubunda öne çıkarken bizim çalışmamızda bu 7. sorunun sorguladığı korse ile görünmekten duydukları kaygı daha fazla öne çıkmıştır

Bu durum Türk adolesanlarda diğer ülkelerdekine göre daha az sporla ilgili olmaları ile ilişkili olabilir.

Bad Sobernheim Stres Sorgulama Formu kısa ve kolay uygulanabilir olma özelliği ile klinik değerlendirmelerde ve bilimsel araştırmalarda kullanılabilir. Çalışmamızda elde edilen yüksek korelasyon oranları soruların az sayıda olması ve cevapların kesin yargılar içermesinden kaynaklanıyor olabilir.

Bu çalışmada, Türkçe'ye çevrilen BSSS Formu'nun AIS nedeniyle gövde ortezi kullanan Türk hastalarda güvenle kullanılabileceği sonucuna varıldı. Bu çalışmanın en önemli özelliği skolyoz nedeniyle korse kullanan adolesanlarda stresi değerlendirecek ilk Türkçe sorgulama formunun oluşturulmuş olmasıdır. 


\section{Çıkar Çatışması:}

Yazarlar herhangi bir çıkar çatışması bildirmemişlerdir.

\section{Kaynaklar}

1. Weiss HR. "Best Practise" in Conservative Scoliosis Care. Bad Sobernheim: Druck und Bindung; 2007. p. 7-14.

2. Oxborrow NJ. Assessing the child with scoliosis: the role of surface topography. Arch Dis Child 2000;83:453-55.

3. Reamy BV, Slakey JB. Adolescent Idiopathic Scoliosis: Review and Current Concepts. Am Fam Physician 2001;64:111-6.

4. Extrapolation of Prevalence Rate of Scoliosis to Countries and Regions. Available form:s URL:http://www.wrongdiagnosis.com/s/scoliosis/statscountry.htm. Accessed December 17,2010.

5. Çilli K, Tezeren G, Tas T, Bulut O, Öztürk H, Öztemur Z, et al. Sivas il merkezinde skolyoz için okul taraması. Acta Orthop Traumatol Turc 2009;43:426-30.

6. Giresun'da Öğrencilere Yönelik Skolyoz Taraması. Available form:s URL:http://www.giresunsaglik.gov.tr/index.php?option=com ontent\&view=article\&id=816:12-okuldaki-skolyoz-taramasi-sonaerdi\&catid=1:son-haberler. Accessed January 30,2011.

7. Skolyoz Destek Grubu. Available form:s URL: http://www.skolyozforum.com

8. Aulisa AG, Guzzanti V, Perisano C, Marzetti E, Specchia A, Marco Gali M, et al. Determination of quality of life in adolescents with idiopathic scoliosis subjected to conservative treatment. Scoliosis 2010;5:21.

9. SOSORT guideline committee, Weiss HR, Negrini S, Rigo M, Kotwicki T, Hawes MC, Grivas TB, et al. Indications for conservative management of scoliosis. Scoliosis 2006;1:5.

10. Açıkgöz T, Tümer Y. Skolyozun Breys Uygulaması ile yapılan Konservatif Tedavisi. T Klin J Med Res 1985;3:136-40.

11. Savaş S. Skolyozun konservatif tedavisi. SDÜ Tıp Fak Derg 2003;10:33-8.

12. Lenssinck MLB, Frijlink AC, Berger MY, Bierma-Zeinstra SMA, Verkerk $K$, Verhagen AP. Effect of Bracing and Other Conservative Interventions in the Treatment of Idiopathic Scoliosis in Adolescents: A Systematic Review of Clinical Trials. Phys Ther 2005;85:1329-39.

13. Weiss HR ,Goodall D.Scoliosis Rehabilitation International Encyclopedia of Rehabilitation. Available form:s URL:http://cirrie.buffalo.edu/ encyclopedia/ en/article/49. Accessed January 23,2011.
14. Weiss HR, Werkmann M, Stephan C. Brace related stress in scoliosis patients-Comparison of different concepts of bracing. Scoliosis 2007;2:10.

15. Kinal E, Kotwicki T, Stryla W, Szulc A. First experience with BSSQ Questionnaire. Proceedings of the 3rd. International Conference on Conservative Management of Spinal Deformities \& Scientific meeting of the SOSORT; 2006 April 7- 8, Ponzan, Poland.

16. Botens-Helmus C, Klein R, Stephan C. The reliability of the Bad Sobernheim Stress Questionnaire (BSSQbrace) in adolescents with scoliosis during brace treatment. Scoliosis 2006;1:22.

17. D'Agata E, Testor CP, Rigo M. Spanish validation of Bad Sobernheim Stres Questionnaire (BSSQ (brace).es) for adolescents with braces. Scoliosis 2010;5:15.

18. Kotwicki T, Kinel E, Stryła W, Szulc A. Estimation of the stress related to conservative scoliosis therapy: an analysis based on BSSQ questionnaires. Scoliosis 2007;2:1.

19. Beaton D, Bombardier C, Guillemin F, Ferraz M. Guidelines for the Process of Cross-Cultural Adaptation of Self-Report Measures. Spine (Phila Pa 1976) 2000:3186-91.

20. Salter K, Jutai JW, Teasell R, Foley NC, Bitensky I, Bayley M. Issues for selection of outcome measures in stroke rehabilitation: ICF activity. Disabil Rehabil 2005;27:315-40.

21. Bland JM, Altman DG. Cronbach's alpha. BMJ 1997;314:572.

22. Wilson CB. Understanding stress and the quality of life for adolescent children of clergy: A retrospective study. Available form:s URL:http://proquest.umi.com/pqdlink?did=2098059301 \&Fmt=7\&clientl.d=79356\&RQT=309\&VName=PQD. Accessed December 04,2010.

23. Vasiliadis E, Grivas TB, Gkoltsiou V. Development and preliminary validation of Brace Questionnaire (BrQ): a new instrument for measuring quality of life of brace. Scoliosis 2006;1:7.

24. Aulisa AG, Guzzanti V, Perisano C, Marzetti E, Specchia A, Galli M, et al. Determination of quality of life in adolescents with idiopathic scoliosis subjected to conservative treatment. Scoliosis 2010,5:21.

25. Misterska E, Głowacki M, Harasymczuk J. Polish adaptation of Bad Sobernheim Stress Questionnaire-Brace and Bad Sobernheim Stress Questionnaire-Deformity. Eur Spine J 2009;18:1911-9. 